Revista de
Economild
Contemporâned

\title{
MUDANÇA ESTRUTURAL E PRODUTIVIDADE DO TRABALHO NO BRASIL NOS ANOS 2000: BÔNUS OU ÔNUS ESTRUTURAL?
}

\begin{abstract}
Felipe Queiroz Silva ${ }^{a}$
a Professor Adjunto da Faculdade de Administração, Ciências Contábeis e Ciências Econômicas da Universidade Federal de Goiás (FACE/UFG). Goiânia, GO, Brasil. ORCID: https://orcid.org/0000-0003-4246-3292.
\end{abstract}

Recebido em 05 junho 2020

Aprovado em 12 fevereiro 2021

RESUMO: O objetivo deste artigo é analisar a contribuição das mudanças da estrutura produtiva da economia brasileira para o incremento da produtividade do trabalho no país entre 2000 e 2018. Para responder essa questão, analisa-se indicadores estruturais da economia brasileira com o auxílio de uma decomposição da produtividade do trabalho de cada atividade econômica para o resultado agregado, levando-se em consideração os efeitos da participação do emprego e dos preços relativos dos setores. O artigo também fornece uma sistematização nova sobre o padrão de especialização da economia brasileira em termos de bônus ou ônus estrutural e análises por meio de classificações setoriais. Os resultados encontrados sugerem que, pelo menos até 2013, o baixo crescimento da produtividade do trabalho agregado no Brasil está mais relacionado com uma perda de eficiência produtiva da indústria e dos serviços mais intensivos em tecnologia do que um possível processo de desindustrialização. Desde 2013, no entanto, há sinais de ônus estrutural na economia brasileira, ou seja, uma mudança estrutural para atividades com menor crescimento da produtividade. Isso é resultado de um processo mais recente de desindustrialização e de aumento da participação do emprego em serviços de baixa intensidade tecnológica.

PALAVRAS-CHAVE: mudança estrutural; produtividade; desindustrialização; economia brasileira.

CLASSIFICAÇÃO JEL: L16; O40; 047. 


\title{
STRUCTURAL CHANGE AND LABOR PRODUCTIVITY IN BRAZIL IN THE 2000s: STRUCTURAL BONUS OR STRUCTURAL BURDEN?
}

\begin{abstract}
This article aims to analyze how structural changes in the Brazilian economy contributed to labor productivity growth between 2000 and 2018. To answer this question, structural indicators of the Brazilian economy are analyzed by decomposing the labor productivity of each economic activity for the aggregate result, considering employment share and relative prices effects. This work also provides a new systematization of the specialization pattern in the Brazilian economy regarding structural bonus or structural burden, analyzing them based on sector classifications. Our results suggest that the weak aggregate productivity growth until 2013 is more associated with a loss of productive efficiency in the industry and technology-intensive services than with a possible deindustrialization. However, the Brazilian economy showed signs of structural burden up from 2013; that is, a structural change towards activities with lower productivity growth, resulting from a more recent process of deindustrialization and increased participation of employment in low-tech services.
\end{abstract}

KEYWORDS: structural change; productivity; deindustrialization; Brazilian economic. 


\section{INTRODUÇÃO}

É consenso na literatura econômica que o aumento da produtividade é o principal responsável para o crescimento econômico sustentado de longo prazo dos países. Isso pode explicar o baixo crescimento do Brasil nos últimos 40 anos, já que dados e pesquisas sobre o tema evidenciam o baixo crescimento da produtividade agregada do país nesse período (DE NEGRI; CAVALCANTE, 2014). Um aspecto bastante discutido seria que o crescimento da produtividade está relacionado com mudanças na sua estrutura produtiva, caracterizadas por mudanças relativas à participação das atividades econômicas no Produto Interno Bruto (PIB) e à migração de trabalhadores entre os setores econômicos. Historicamente, o processo de desenvolvimento econômico dos países pode ocorrer em estágios de mudança estrutural dessas variáveis ao longo do tempo, de setores menos produtivos (bens e serviços básicos) para setores mais produtivos (bens e serviços sofisticados).

Nos anos 2000, acontecimentos como a ascensão da China e de outros países asiáticos na indústria global, que impactou na reprimarização da pauta de exportações do Brasil, bem como de um possível processo de desindustrialização, podem esclarecer a relação entre mudança estrutural e produtividade agregada. Isso ocorreria pelo fato de as atividades industriais serem responsáveis por abrigar setores mais intensivos em tecnologia, que, consequentemente, apresentam níveis maiores de produtividade. Por outro lado, percebe-se que várias economias desenvolvidas vêm apresentando, nos anos mais recentes, uma estrutura que vem diminuindo a participação no PIB de setores ligados a indústrias para um aumento na participação de serviços intensivos em conhecimento. Isso vem acendendo o debate sobre mudança estrutural, desindustrialização e o papel dos serviços na manufatura e como atividades dinâmicas e inovadoras (RODRIK, 2016).

Nesse contexto, o objetivo deste artigo é analisar a contribuição das mudanças da estrutura produtiva da economia brasileira para o incremento da produtividade do trabalho no país nos anos 2000. Mais precisamente, objetiva-se analisar em que medida houve mudanças na estrutura produtiva da economia brasileira no período recente, e quais os efeitos dessas supostas mudanças sobre os indicadores de produtividade do trabalho. Em outras palavras, seriam as mudanças estruturais na economia brasileira, particularmente a queda da participação da indústria no PIB, responsáveis pelo baixo crescimento da produtividade agregada no país? Se sim, quais setores mais contribuíram para o desempenho recente da produtividade no Brasil?

Para responder essas questões, analisa-se a mudança estrutural da economia brasileira nos anos 2000, fazendo-se uma análise shift-share da produtividade do trabalho de cada atividade econômica para o resultado agregado, levando-se em conta as mudanças na 
composição das ocupações e as mudanças no comportamento dos preços relativos. O artigo utiliza a base de dados do Sistema de Contas Nacionais (SCN), disponibilizada pelo Instituto Brasileiro de Geografia e Estatística (IBGE), disponível de forma contínua e com um nível de agregação de atividades mais amplo e compatíveis entre os anos 2000 e 2018. Para aprofundar a análise, utilizou-se o sistema de classificação de intensidade tecnológica das atividades econômicas da Organization for Economic Cooperation and Development (OECD, 2011) e uma sistematização nova a respeito do padrão de especialização da economia brasileira em termos de mudança estrutural via aumento da participação de setores mais produtivos (bônus estrutural) ou menos produtivos (ônus estrutural). Privilegiou-se também a análise dos serviços de maior conteúdo tecnológico e diretamente ligados às empresas e ao setor industrial.

Um estudo mais recente sobre mudança estrutural e seus efeitos na produtividade na economia brasileira é importante para analisar até que ponto mudanças estruturais como um possível processo de desindustrialização e o papel dos serviços impactam diretamente no desempenho da economia brasileira. Mais do que isso, o trabalho propõe analisar padrões distintos de indústrias e serviços, ressaltando os aspectos de intensidade tecnológica dos setores. Além desta introdução, o artigo está dividido em mais cinco seções. A primeira seção apresenta o debate teórico e empírico sobre a relação entre mudança estrutural e produtividade. A segunda seção apresenta a metodologia de decomposição empregada, bem como a classificação setorial proposta e a base de dados. A terceira seção mostra o contexto empírico da economia brasileira nos anos 2000, fazendo-se uma análise da evolução da estrutura produtiva com base em indicadores de valor adicionado, ocupações e produtividade. A quarta seção apresenta e discute os resultados de decomposição da produtividade do trabalho agregada. Por fim, a última seção pontua as considerações finais.

\section{MUDANÇA ESTRUTURAL E PRODUTIVIDADE: ABORDAGENS TEÓRICAS E EMPÍRICAS}

A literatura sobre mudança estrutural é antiga e permeia o debate sobre desenvolvimento econômico. Krüger (2008) faz uma revisão de várias abordagens sobre o tema com especial foco na relação da mudança estrutural com a produtividade e mudança tecnológica. Como definição, o autor conceitua mudança estrutural como as modificações na participação nos setores de uma economia no que se refere ao valor adicionado e, principalmente, ao emprego. A decomposição desses indicadores ao longo do tempo é utilizada em praticamente todos os estudos teóricos e empíricos sobre o tema. Para os diversos autores analisados por Krüger (2008), a mudança estrutural é fruto de fatores que podem estar relacionados a oferta e/ou a demanda. Pela oferta, o progresso técnico 
pode impulsionar ganhos de produtividade diferenciados entre setores e gerar uma consequente realocação do trabalho. Pela demanda, a saturação por determinados tipos de bens, mudanças nos preços relativos e preferência dos consumidores podem mudar o padrão de consumo da população.

Essa noção de mudanças na composição de emprego parte das observações iniciais de Fisher (1939) e Kuznets (1973) do que ficou conhecido na literatura como a hipóteses dos três setores. Nessa hipótese, em uma primeira fase do desenvolvimento econômico de um país, o setor primário (agricultura, bens básicos) domina o emprego e a produção, enquanto os setores secundários (indústria, bens manufaturados) e terciários (serviços) possuem menor importância. Conforme o país avança em seu desenvolvimento, há o processo de industrialização, aumentando a participação do emprego industrial em detrimento da agricultura. Segundo sistematizado por Krüger (2008), o progresso tecnológico no setor primário supre a população em uma quantidade maior do que o seu próprio crescimento. Com a saturação de bens básicos e o aumento da demanda por bens manufaturados, há a migração de trabalhadores rurais para a indústria. Com as maiores remunerações vindas do emprego industrial, há um aumento do padrão de vida da população, que passa a demandar cada vez mais bens manufaturados e, depois, produtos do setor terciário. Para gerar estes produtos, que estão associados a uma alta elasticidade-renda da demanda, há, por fim, uma grande migração de trabalhadores da indústria para os serviços.

No processo de desenvolvimento econômico da hipótese dos três setores, alguns autores associam a primeira grande mudança estrutural da agricultura para a indústria para o que se convencionou chamar de bônus estrutural (CHENERY, 1986; SYRQUIN, 1988). Neste caso, há o deslocamento do emprego dos setores de menor produtividade (agricultura) para setores de maior produtividade (indústria). A indústria é vista como um macrossetor mais produtivo, pois possui, entre outras características, maior relação capital-trabalho, maiores ganhos de economias de escala, maior nível de qualificação da mão de obra e maior intensidade tecnológica. Desta maneira, sob a hipótese de bônus estrutural, há uma relação positiva entre mudança estrutural e crescimento econômico, pois há a realocação de recursos (trabalhadores e capital) para setores de maior produtividade. Para esses autores, o processo de industrialização é um componente chave para o aumento da renda dos países.

A abordagem de bônus estrutural, no entanto, pouco se aprofunda na segunda mudança prevista na hipótese dos três setores e que claramente é observada atualmente na estrutura produtiva de vários países: a migração do emprego e a menor participação no PIB do setor industrial em detrimento do setor de serviços, ou seja, a um processo de desindustrialização. Esse aspecto é ressaltado por Baumol (1967) e revisitado por Baumol, Blackman e Wolff (1985) para o que ficou conhecido como a doença de custos 
dos serviços e que, para fazer frente ao bônus estrutural, Peneder (2003) chamou de ônus estrutural.

Neste caso, Baumol (1967) e Baumol, Blackman e Wolff (1985) desenvolvem um modelo de crescimento desbalanceado, envolvendo um setor "progressivo", de maior crescimento da produtividade do trabalho, e um setor "estagnado", com menor crescimento desta. O que diferencia esses dois setores é a forma como o trabalho é empregado. Enquanto no setor progressivo o trabalho é utilizado como insumo de produção (indústria), no setor estagnado é utilizado como produto final (serviços). Devido ao potencial limitado dos serviços em aumentar a produtividade do trabalho, os custos e os preços relativos destes tendem a crescer, já que os salários continuam a aumentar. Por outro lado, o progresso técnico, o aprofundamento de capital e os ganhos de escala dos setores da manufatura tendem a compensar os aumentos salariais. Assim, com o crescimento da produtividade, há demissões de trabalhadores do setor progressivo que é realocada no setor estagnado. A consequência natural e inevitável é o aumento na participação do emprego e na produção dos serviços em detrimento da manufatura, acarretando o declínio da produtividade agregada. Neste caso, ao contrário da relação positiva entre mudança estrutural e crescimento econômico na hipótese de bônus estrutural, tem-se uma relação negativa entre as variáveis, acarretando um ônus estrutural.

Do ponto de vista empírico, vários autores vêm buscando observar a relação entre mudança estrutural e produtividade em diversos países. Enquanto o efeito de bônus estrutural parece ser mais claro na realocação do trabalho da agricultura para a indústria nos estágios iniciais de desenvolvimento dos países (SYRQUIN, 1988; FAGERBERG, 2000; DIAO; KWEKA; MCMILLAN, 2018), os movimentos da indústria para os serviços ou até mesmo movimentos internos à manufatura, de indústrias de menor para maior produtividade, não parecem evidentes. Ao contrário, a maioria dos trabalhos empíricos discutidos a seguir sinalizam uma caraterística de neutralidade da mudança estrutural sobre a produtividade agregada ou até mesmo de ônus estrutural.

A relação empírica quantitativa entre mudança estrutural e produtividade ganhou amplitude com a metodologia de análise de decomposição ou de shift-share apresentado por Fagerberg (2000). O autor analisou somente os setores da manufatura de 39 países entre 1973 e 1990, no qual verificou que não há, em média, efeitos da mudança estrutural sobre a produtividade agregada. No entanto, o autor observa que os países que aumentaram a participação de indústrias mais intensivas em tecnologias experimentaram maior crescimento da produtividade do que outros países. Segundo Fagerberg (2000), setores mais dinâmicos do ponto de vista da tecnologia parecem gerar menos empregos, i.e., baixa elasticidade do emprego em relação a produtividade. Como a mensuração da mudança estrutural é feita com base na realocação de trabalhadores, isso pode explicar neutralidade do efeito bônus estrutural, evidenciando mais os efeitos intrassetoriais. 
A metodologia de Fagerberg (2000) para setores da indústria manufatureira foi replicada por diversos autores em diversos países. Estes estudos chegaram basicamente na mesma conclusão de uma relação neutra ou negativa da mudança estrutural sobre a produtividade agregada (TIMMER; SZIRMAI, 2000; PENEDER, 2003; CARREE, 2003). Peneder (2003) resume bem os achados ao analisar que nas indústrias com maiores taxas de crescimento da produtividade a expansão da produção não consegue acompanhar o ritmo de queda da mão de obra. Já Singh (2004) e Chen, Jefferson e Zhang (2011), que analisaram, respectivamente, a Coreia do Sul e a China, observaram que houve efeito de bônus estrutural em décadas anteriores, mas que estes são cada vez menores nos últimos anos. Para o caso da China, país que aumentou muito a sua produção industrial nas últimas décadas, o efeito de bônus estrutural na indústria ocorre, mas em menor intensidade nos últimos anos e em menor grau do que o efeito intrassetorial. Brondino (2019) também observa o mesmo para a China ao analisar toda a economia entre 1995 e 2009.

Para o caso da economia como um todo, ao levantar também a questão da mudança estrutural via aumento da participação dos serviços, a maioria dos estudos observam a tendência de ônus estrutural (TIMMER; VRIES, 2009; VRIES; TIMMER; VRIES, 2015; PADILLA-PÉREZ; VILLARREAL, 2017; BADRIAH et al., 2019). Ao analisar 19 países da Ásia e América Latina entre 1950 e 2005, Timmer e Vries (2009) chegam à conclusão de que o crescimento agregado é explicado pelo aumento da produtividade nos setores, e não pela realocação do emprego para setores mais produtivos. Os autores destacam também que o crescimento da produtividade dos serviços foi mais importante do que dos setores industriais. Esses resultados contestam a doença de custos dos serviços de Baumol, Blackman e Wolff (1985), já que os serviços também podem agregar atividades mais modernas intensivas em conhecimento e com alto crescimento da produtividade, como é o caso de serviços de comunicação, desenvolvimento de softwares, pesquisa e algumas atividades prestadas às empresas.

Por outro lado, ao analisar 38 países entre 1990 e 2005, McMillan, Rodrik e VerduzcoGallo (2014) mostraram que os países da Ásia experimentaram mudanças estruturais que melhoraram a produtividade, enquanto os países da África e da América Latina experimentaram mudanças que a reduziram. Essa diferença ocorreu devido aos padrões estruturais encontrados nesses grupos de países nos últimos anos: enquanto na Ásia o trabalho migrou de atividades de baixa para alta produtividade, na América Latina e na África ocorreu o contrário. Padilha-Pérez e Villarreal (2017) também observaram esse comportamento para o México entre 1990 e 2014, destacando que os baixos níveis de crescimento da produtividade agregada no país ocorreram devido a um processo de desindustrialização, ou seja, migração da mão de obra para os serviços, que tiveram baixo crescimento da produtividade. 
No Brasil, Rocha (2007), Squeff e De Negri (2014) e Jacinto e Ribeiro (2015) também aplicaram técnicas shift-share com o objetivo de avaliar a relação entre mudança estrutural e produtividade do trabalho no país. Rocha (2007) avaliou as mudanças dos setores da indústria entre 1970 e 2001, e observou o efeito de ônus estrutural, sugerindo uma especialização crescente da indústria nos segmentos em que a produtividade cresce mais lentamente. Já Squeff e De Negri (2014) observaram os efeitos da mudança estrutural para toda a economia entre 2001 e 2009. Os autores verificaram que o crescimento da produtividade agregada no Brasil foi baixa, com efeito neutro de mudança estrutural e maior contribuição dos serviços devido a sua alta participação na economia. Por fim, Jacinto e Ribeiro (2015) verificaram o melhor desempenho da produtividade dos serviços do que da indústria para a primeira década dos anos 2000 no Brasil, não observando os efeitos de doenças de custos e nem de bônus estrutural. Esses estudos sugerem uma especialização para atividades de menor crescimento da produtividade no país, mas que não necessariamente estão relacionados a um processo de desindustrialização ou de perda de produtividade dos serviços.

Dessa maneira, este artigo visa contribuir para a literatura empírica de mudança estrutural e produtividade ao analisar dados mais recentes da economia brasileira em uma série compatível e mais desagregada entre 2000 e 2018. Classificações econômicas mais desagregadas, que contemplem padrões de concorrência e de intensidade tecnológica, são importantes para ressaltar o perfil de especialização da economia. Temas relacionados a um possível processo de desindustrialização no Brasil nos anos 2000, bem como a crise econômica mais recente a partir de 2014 e o aumento da informalidade do trabalho, também podem sinalizar aspectos importantes na relação entre mudança estrutural e produtividade.

\section{METODOLOGIA: DECOMPOSIÇÃO DA PRODUTIVIDADE DO TRABALHO AGREGADA}

Para analisar a contribuição dos setores econômicos na produtividade do trabalho da economia, utilizou-se o método de shift-share apresentado por Diewert (2015) com base em Tang e Wang (2004), e que também foi utilizado por Squeff e De Negri (2014). O objetivo é decompor a produtividade do trabalho em componentes relacionados à contribuição da produtividade dentro de cada atividade econômica, às mudanças estruturais na composição das ocupações e às mudanças no comportamento dos preços relativos. Diferentemente da maioria dos trabalhos analisados na seção anterior que também utilizaram a técnica de shift-share, o método de Diewert (2015) é mais robusto por levar em consideração os efeitos das mudanças de preços relativos sobre a produtividade agregada. Como os dados das Contas Nacionais na maioria dos países 
hoje, incluindo o Brasil, utilizam base móvel nos quais os preços relativos dos setores mudam constantemente, deve-se levar em consideração esse comportamento. ${ }^{1}$ Essa decomposição é representada pela equação (1):

$$
y_{t}=\frac{\Sigma_{i} Q_{t}^{i}}{P_{t} L_{t}}=\frac{\sum_{i}\left(\frac{Y_{t}^{i} P_{t}^{i} L_{t}^{i}}{L_{t}^{i}}\right)}{P_{t} L_{t}}=\frac{\Sigma_{i}\left(P_{t}^{i} L_{t}^{i} y_{t}^{i}\right)}{P_{t} L_{t}}=\Sigma_{i}\left(y_{t}^{i} p_{t}^{i} l_{t}^{i}\right)
$$

Em (1) o subscrito $t$ indica tempo; $i$, o setor econômico; $Y$, o valor adicionado a preços constantes; $Q$, o valor adicionado a preços correntes; $L$, a quantidade de trabalhadores; e $P$ o deflator do valor adicionado.

Dessa maneira, a equação (1) pode ser entendida como: a produtividade do trabalho de toda a economia a preços constantes no tempo $t\left(y_{t}=\frac{Y_{t}}{L_{t}}\right)$ é igual a razão entre o somatório do valor adicionado dos $i$ setores a preços correntes $\left(\sum_{i} Q_{t}^{i}\right)$ e o produto entre o deflator do valor adicionado total $\left(P_{t}\right)$ e a quantidade total de trabalhadores $\left(L_{t}=\sum_{i} L_{t}^{i}\right)$. Por meio de um rearranjo algébrico, verifica-se que a produtividade do trabalho total a preços constantes é o somatório do produto da produtividade do trabalho a preços constantes do setor $i\left(y_{t}^{i}=\frac{Y_{t}^{i}}{L_{t}^{i}}\right)$, do preço relativo do setor $i\left(p_{t}^{i}=\frac{P_{t}^{i}}{P_{t}}\right)$ e da participação das ocupações do setor $i$ no total das ocupações $\left(l_{t}^{i}=\frac{L_{t}^{i}}{L_{t}}\right)$.

Definindo $q_{t}^{i}=\frac{Q_{t}^{i}}{Q_{t}}$ como a participação do valor agregado a preços correntes do setor $i$ no valor agregado total; $\hat{y}_{t}=\frac{\left(y_{t}-y_{t-1}\right)}{y_{t-1}}$ como a variação percentual da produtividade do trabalho total a preços constantes entre os anos $t$ e $t-1 ; \hat{y}_{t}^{i}=\frac{\left(y_{t}^{i}-y_{t-1}^{i}\right)}{y_{t-1}^{i}}$ como a variação percentual da produtividade do trabalho do setor $i$ a preços constantes entre os anos $t$ e $t-1 ; \hat{l}_{t}^{i}=\frac{\left(l_{t}^{i}-l_{t-1}^{i}\right)}{l_{t-1}^{i}}$ como a variação percentual da participação das ocupações do setor $i$ no total das ocupações entre os anos $t$ e $t-1$ e $\hat{p}_{t}^{i}=\frac{\left(p_{t}^{i}-p_{t-1}^{i}\right)}{p_{t-1}^{i}}$ como a variação percentual dos preços relativos do setor $i$ entre os anos $t$ e $t-1$, temos que a variação da produtividade do trabalho total pode ser representada na equação (2), como definido em Diewert (2015): $\hat{y}_{t}=\sum_{i} q_{t-1}^{i} \hat{y}_{t}^{i}+\sum_{i} q_{t-1}^{i} \hat{l}_{t}^{i}+\sum_{i} q_{t-1}^{i} \hat{p}_{t}^{i}+\sum_{i} q_{t-1}^{i} \hat{y}_{t}^{i} \hat{l}_{t}^{i}+\sum_{i} q_{t-1}^{i} \hat{y}_{t}^{i} \hat{p}_{t}^{i}+\sum_{i} q_{t-1}^{i} \hat{l}_{t}^{i} \hat{p}_{t}^{i}+$ $\sum_{i} q_{t-1}^{i} \hat{y}_{t}^{i} \hat{l}_{t}^{i} \hat{p}_{t}^{i}$

Com a utilização do termo $q_{t}^{i}$, ou seja, a participação do valor adicionado do setor $i$ no valor adicionado total, a decomposição da equação (2) define que a variação da produtividade do trabalho total da economia é uma média ponderada das participações do valor agregados dos setores econômicos, dando peso para o tamanho dos setores na economia. A produtividade do trabalho total é uma decomposição que pode ser 1 Para uma discussão sobre os métodos de decomposição shift-share quanto ao uso em bases móveis das
Contas Nacionais ver Avillez (2012). 
analisada em quatro efeitos: i) efeito direto ou eficiência intrassetorial $\left(\sum_{i} q_{t-1}^{i} \hat{y}_{t}^{i}\right)$, que mede a contribuição da variação da produtividade do trabalho de cada setor para o resultado agregado; ii) efeito composição do trabalho $\left(\sum_{i} q_{t-1}^{i} \hat{l}_{t}^{i}\right)$, que mede a contribuição da variação da participação de ocupações (mudança estrutural); iii) efeito preço $\left(\sum_{i} q_{t-1}^{i} \hat{p}_{t}^{i}\right)$, que mede a contribuição das variações de preços relativos; e iv) efeito interação (soma dos quatro componentes restantes da Equação 2), que possui difícil interpretação econômica, já que decorre do próprio processo de manipulação algébrica para fechar a equação.

Esse tipo de análise com quatro efeitos foi utilizado para a economia brasileira por Squeff e De Negri (2014). No entanto, como o efeito interação é a soma dos termos de segunda e terceira ordem da equação (2), e como na maioria dos casos somente os termos de primeira ordem serão relevantes e de maior magnitude, Diewert (2015) propõe consolidar os sete termos em apenas três. Isso é feito de maneira simétrica, atribuindo os termos de segunda e terceira ordem ao termo de primeira ordem. Ao nível dos setores, tem-se os três componentes que formarão a variação da produtividade agregada: i) efeito eficiência intrassetorial $\left(\Delta X_{i}\right)$; ii) efeito composição $\left(\Delta L_{i}\right)$; e iii) efeito preço $\left(\Delta P_{i}\right)$ :

$$
\begin{aligned}
& \Delta X_{i t}=q_{t-1}^{i} \hat{y}_{t}^{i}\left\{1+\left(\frac{1}{2}\right) \hat{p}_{t}^{i}+\left(\frac{1}{2}\right) \hat{l}_{t}^{i}+\left(\frac{1}{3}\right) \hat{p}_{t}^{i} \hat{l}_{t}^{i}\right\} \\
& \Delta L_{i t}=q_{t-1}^{i} \hat{l}_{t}^{i}\left\{1+\left(\frac{1}{2}\right) \hat{y}_{t}^{i}+\left(\frac{1}{2}\right) \hat{p}_{t}^{i}+\left(\frac{1}{3}\right) \hat{y}_{t}^{i} \hat{p}_{t}^{i}\right\} \\
& \Delta P_{i t}=q_{t-1}^{i} \hat{p}_{t}^{i}\left\{1+\left(\frac{1}{2}\right) \hat{y}_{t}^{i}+\left(\frac{1}{2}\right) \hat{l}_{t}^{i}+\left(\frac{1}{3}\right) \hat{y}_{t}^{i} \hat{l}_{t}^{i}\right\}
\end{aligned}
$$

Assim, as contribuições setoriais acima somam a taxa de crescimento da produtividade agregada $\left(\hat{y}_{t}\right)$

$$
\hat{y}_{t}=\underbrace{\sum_{i} \Delta X_{i t}}_{\begin{array}{c}
\text { Eficiência } \\
\text { Intrassetorial }
\end{array}}+\underbrace{\sum_{i} \Delta L_{i t}}_{\text {Composição }}+\frac{\sum_{i} \Delta P_{i t}}{\text { Preço }}
$$

A estrutura montada pela equação (6) é capaz de mensurar os efeitos da produtividade setorial, das mudanças de ocupações e de preços relativos sobre a produtividade agregada para qualquer intervalo de tempo que se queira analisar. Se os efeitos da eficiência intrassetorial, composição e preço forem positivas, significa, respectivamente, que o crescimento da produtividade dos setores contribuiu para o crescimento da produtividade agregada; que houve um crescimento da produtividade 
agregada em decorrência do aumento da participação dos setores que mais cresceram individualmente (bônus estrutural); e que as mudanças dos preços relativos foram favoráveis para a economia.

No entanto, como analisado empiricamente por Fagerberg (2000), pode ser que uma atividade esteja perdendo participação na economia por meio de um crescimento da sua produtividade via diminuição das ocupações. Neste caso, tem-se um ônus estrutural via aumento da eficiência produtiva. Em outros casos, como analisado por Baumol, Blackman e Wolff (1985), pode ser que atividades com menor crescimento da produtividade estejam aumentando a sua participação, o que pode ser chamado de ônus estrutural via aumento da ineficiência produtiva. Já nas hipóteses de bônus estrutural, o bônus pode vir tanto de um aumento da participação dos setores que mais crescem a sua produtividade (bônus estrutural via aumento da eficiência), quanto por uma redução da participação dos setores que decrescem a sua produtividade (bônus estrutural via diminuição da ineficiência). Neste sentido, em uma análise mais detalhada dos setores, é importante perceber os sinais dos efeitos eficiência intrassetorial e composição da equação (6). O Quadro 1 resume a análise comparativa entre estes dois efeitos.

\section{Quadro 1 - Efeito especialização dinâmica: relação eficiência intrassetorial e composição}

\begin{tabular}{|ccc|}
\hline & Efeito Composição Positivo & Efeito Composição Negativo \\
\hline \multirow{3}{*}{ Efeito Eficiência Intrasetorial } & Bônus Estrutural Eficiente (Bônus +) & Ônus Estrutural Eficiente (Ônus +) \\
Positivo & Aumento da participação de setores & Diminuição da participação de setores \\
& mais produtivos via crescimento da & mais produtivos via crescimento da \\
& produtividade do trabalho destes. & produtividade do trabalho destes. \\
\hline & Ônus Estrutural Ineficiente (Ônus -) & Bônus Estrutural Ineficiente (Bônus -) \\
Efeito Eficiência Intrasetorial & Aumento da participação de setores & Diminuição da participação de setores \\
Negativo & menos produtivos via decrescimento da & menos produtivos via decrescimento da \\
& produtividade do trabalho destes. & produtividade do trabalho destes. \\
\hline
\end{tabular}

Fonte: Elaboração própria.

A sistematização proposta no Quadro 1 para um maior detalhamento dos efeitos individuais das atividades para a economia é importante para captar as nuances da relação entre mudança estrutural e produtividade agregada. Em uma técnica de shiftshare semelhante, mas sem levar em consideração os efeitos de preços relativos, Timmer e Szirmai (2000) apresentaram uma mensuração do efeito conjunto entre eficiência intrassetorial e composição, chamado de efeito especialização dinâmica, que seria equivalente ao quarto termo da equação (2). Para melhorar o poder de síntese e, ao mesmo tempo, levar em consideração os efeitos dos preços relativos, preferiu-se seguir a consolidação proposta por Diewert (2015) na equação (6). Neste caso, o efeito 
especialização dinâmica é analisado qualitativamente pela combinação de sinais dos efeitos eficiência intrassetorial e composição sistematizado no Quadro 1.

Por fim, uma discussão e limitação importante para análise de decomposição proposta é o próprio cálculo da produtividade. O presente artigo apresenta uma decomposição que parte de uma mensuração tradicional de produtividade do trabalho, i.e., o valor adicionado divido pelo número de trabalhadores. Essa é a forma de mensuração da grande maioria dos trabalhos que aplicaram técnicas de shift-share discutidos na seção anterior. Outros autores, no entanto, chamam atenção para a limitação da mensuração da produtividade do trabalho ao não levar em consideração outros fatores de produção, como o capital empregado, preferindo o uso da produtividade total dos fatores com base em Solow (1957). Este tipo de mensuração, além de também possuir as suas limitações (hipóteses simplificadoras como retornos constantes de escala e calculado com base em um resíduo), é de difícil aplicação na economia brasileira devido à limitação de dados de estoque de capital em nível setorial.

Já De Juan e Febrero (2000) chamam atenção para uma mensuração da produtividade por meio da ótica de subsistemas ou setores verticalmente integrados com base em Sraffa (1960) e Pasinetti (1973) e aplicável em matrizes de insumoproduto. Segundo os autores, esse método de estimação é mais robusto, pois leva em consideração não apenas o trabalho empregado de uma determinada atividade econômica para o cálculo de sua produtividade, mas também o trabalho empregado de toda a sua cadeia produtiva (consumo intermediário). Isso faz com que o cálculo da produtividade capte a interdependência das atividades econômicas e, como é operado em unidades físicas, evita problemas na deflação do valor adicionado, já que este é uma medida monetária calculada de forma residual (diferença entre o valor bruto de produção e consumo intermediário) impactada pelas variações nos preços relativos. Este problema de deflação é parcialmente resolvido com o método de decomposição de Diewert (2015) utilizado ao incorporar deflatores setoriais ao invés de um deflator geral da economia. Ademais, o uso de matrizes de insumoproduto nacionais em uma série ampla e compatível em níveis setoriais mais desagregadas possui várias limitações de compatibilidade, ${ }^{2}$ enquanto o uso de decomposição proposto é largamente utilizado na literatura e útil para comparações e discussões com estudos anteriores. 2 Um esforço de estimação anual de matrizes insumo-produto compatíveis no Brasil pode ser visto em
Passoni (2019). 


\subsection{BASE DE DADOS E CLASSIFICAÇÃO SETORIAL}

Diante de constantes mudanças de metodologias e de classificações setoriais das Contas Nacionais elaboradas e disponibilizadas pelo IBGE, é difícil compatibilizar uma série mais longa de dados para uma análise precisa. A série compatível mais longa e recente das contas nacionais disponíveis é o Sistema de Contas Nacionais Trimestrais (SCNT), compreendendo os trimestres do intervalo de anos 1996 a 2020. O problema é que essa série possui um número de atividades econômicas muito limitado, agregando, por exemplo, toda a indústria manufatureira em apenas um setor. Uma alta agregação das atividades enfraquece o efeito composição e não leva em consideração as diferenças de intensidades tecnológicas muito distintas de indústrias e serviços. Para um maior detalhamento setorial, a alternativa é utilizar as tabelas de recursos e usos da série retropolada em 51 atividades do Sistema de Contas Nacionais (SCN), que compreende os anos entre 2000 e 2018.

No entanto, níveis muito desagregados dificultam a identificação de tendências e regularidades nos dados econômicos. Nesse sentido, optou-se por analisar a indústria manufatureira com base na classificação de intensidade tecnológica da OCDE (2011), já amplamente utilizada na literatura econômica sobre inovação. A compatibilização da classificação do SCN com a da OCDE pode ser vista em Cavalcante (2014), no qual a indústria manufatureira é dividida em alta, média-alta, média-baixa e baixa intensidade tecnológica (IT). O restante da indústria é dividido entre a indústria extrativa mineral, serviços industriais de utilidade pública (SIUP) e construção civil. Devido a sua grande heterogeneidade, o setor de serviços foi agrupado com a finalidade de dar destaque para os serviços de maior conteúdo tecnológico e diretamente ligados às empresas e ao setor industrial, como serviços de comunicação e informação, serviços prestados às empresas, serviços de transporte e armazenagem e intermediação financeira. Por fim, serviços básicos muito ligados à demanda final, como educação, saúde, alimentação, serviços gerais e domésticos, foram agrupados como "outros serviços".

\section{CONTEXTO EMPÍRICO: ESTRUTURA E PRODUTIVIDADE NO BRASIL (2000-2018)}

Como primeiro passo da análise de mudança estrutural e produtividade no Brasil, a Figura 1 apresenta a evolução das taxas de crescimento do valor adicionado da economia brasileira e de seus grandes setores econômicos entre 2000 e 2018 . Percebe-se que a economia brasileira nos anos 2000 vem crescendo de maneira lenta e contínua até 2014 , quando passou a ter dois anos seguidos de taxas negativas e voltou a crescer lentamente a partir de 2017. Nesses 18 anos, o valor adicionado total cresceu 50,1\%, ou 2,3\% ao 
ano em média. Para um país em desenvolvimento, o baixo crescimento de longo prazo da economia no Brasil, que nos remete pelo menos desde a década de 1980, põe em evidência um problema estrutural.

No nível mais amplo de desagregação, a Figura 1 mostra que a agropecuária e a indústria extrativa mineral cresceram a taxas muito superiores da economia, enquanto a soma de toda a indústria cresceu a taxas inferiores, principalmente em decorrência do desempenho ruim da indústria de transformação. Os serviços seguiram mais ou menos a mesma trajetória da economia. Desta maneira, percebe-se a importância da agropecuária e da indústria extrativa mineral para o crescimento econômico do Brasil neste período.

\section{Figura 1 - Evolução da taxa de crescimento do valor adicionado no Brasil (a preços} constantes de 2000), 2000-2018 (2000 = 100)

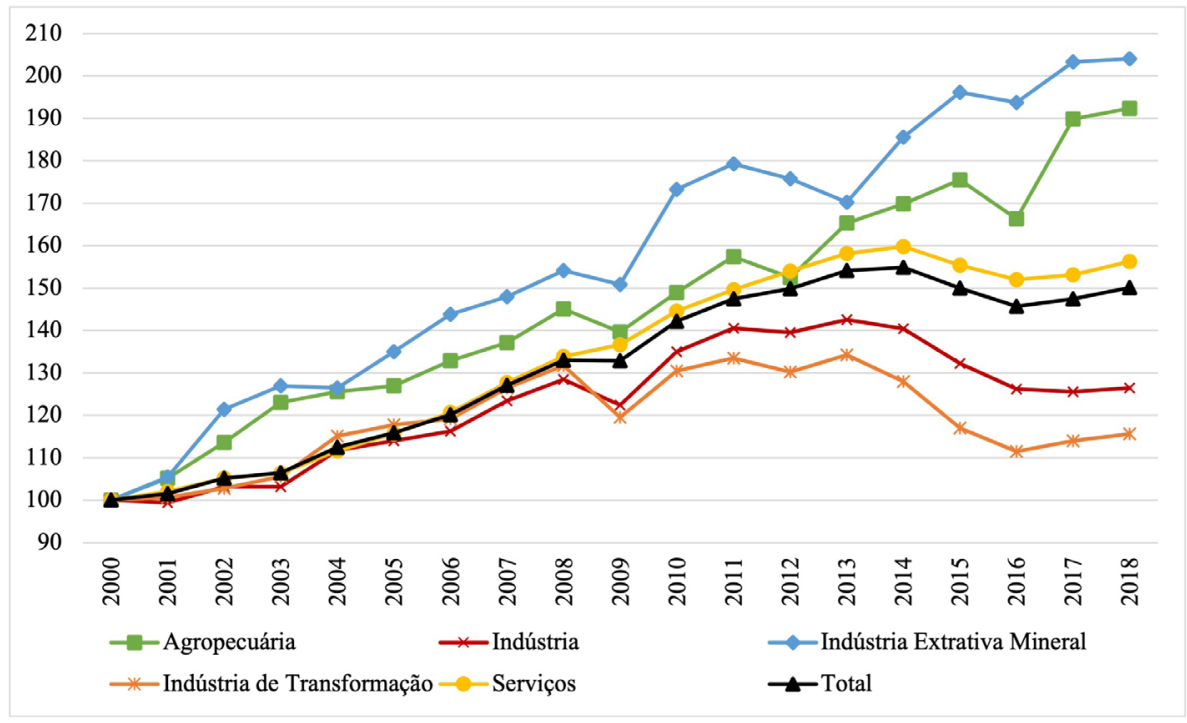

Fonte: Elaboração própria com base em IBGE (2020a).

No entanto, a agricultura e a indústria extrativa mineral representam uma pequena parcela do valor adicionado total. A Tabela 1 apresenta a participação percentual de forma mais desagregada dos setores econômicos no valor adicionado total entre os anos 2000 e 2018. Apesar de uma maior participação ao longo do tempo, a agricultura representou apenas 7,1\% da economia brasileira em 2018, enquanto a indústria extrativa mineral não passou de 1,9\%. Em 18 anos, o que chama mais atenção é a relação inversa entre as participações da agropecuária e dos serviços frente a participação da indústria no valor adicionado da economia brasileira. 
Tabela 1 - Evolução da participação dos setores econômicos no valor adicionado no Brasil (a preços constantes de 2000), 2000-2018 (em \%)

\begin{tabular}{|c|c|c|c|c|c|c|c|c|c|c|}
\hline & 2000 & 2002 & 2004 & 2006 & 2008 & 2010 & 2012 & 2014 & 2016 & 2018 \\
\hline Agropecuária & 5,5 & 6,0 & 6,2 & 6,1 & 6,0 & 5,8 & 5,6 & 6,1 & 6,3 & 7,1 \\
\hline Indústria & 26,7 & 26,2 & 26,6 & 25,9 & 25,8 & 25,4 & 24,9 & 24,2 & 23,2 & 22,6 \\
\hline Indústria Extrativa Mineral & 1,4 & 1,6 & 1,6 & 1,7 & 1,6 & 1,7 & 1,6 & 1,7 & 1,8 & 1,9 \\
\hline Indústria de Transformação & 15,3 & 14,9 & 15,6 & 15,2 & 15,1 & 14,0 & 13,3 & 12,6 & 11,7 & 11,8 \\
\hline Baixa IT & 5,8 & 5,7 & 5,6 & 5,5 & 5,1 & 4,8 & 4,4 & 4,2 & 4,2 & 4,2 \\
\hline Média-Baixa IT & 3,7 & 3,7 & 3,7 & 3,6 & 3,5 & 3,0 & 2,9 & 2,6 & 2,4 & 2,3 \\
\hline Média-Alta IT & 4,1 & 3,9 & 4,5 & 4,36 & 4,5 & 4,4 & 4,1 & 3,8 & 3,2 & 3,4 \\
\hline Alta IT & 1,6 & 1,6 & 1,7 & 1,8 & 2,0 & 1,9 & 2,0 & 2,2 & 2,1 & 2,2 \\
\hline SIUP & 3,1 & 2,9 & 3,0 & 3,0 & 2,9 & 2,9 & 3,0 & 2,8 & 3,2 & 3,3 \\
\hline Construção Civil & 7,0 & 6,8 & 6,4 & 5,9 & 6,1 & 6,9 & 7,3 & 7,3 & 6,3 & 5,4 \\
\hline Serviços & 67,7 & 67,8 & 67,2 & 68,1 & 68,2 & 68,9 & 69,6 & 69,9 & 70,6 & 70,5 \\
\hline Comércio & 8,1 & 7,7 & 7,8 & 7,9 & 8,1 & 8,3 & 8,2 & 8,3 & 7,6 & 7,8 \\
\hline Transporte e Armazenagem & 3,7 & 3,6 & 3,5 & 3,5 & 3,6 & 3,5 & 3,6 & 3,6 & 3,5 & 3,5 \\
\hline Comunicação e Informação & 4,3 & 4,6 & 4,6 & 4,6 & 4,8 & 4,8 & 5,2 & 5,5 & 5,6 & 5,6 \\
\hline Prestados às Empresas & 5,6 & 5,5 & 5,2 & 5,5 & 5,6 & 5,7 & 6,0 & 6,0 & 6,0 & 5,9 \\
\hline Intermediação Financeira & 6,8 & 6,8 & 6,4 & 6,9 & 8,1 & 9,0 & 9,2 & 9,0 & 9,2 & 8,9 \\
\hline Imobiliárias e Aluguéis & 12,2 & 12,5 & 12,8 & 13,0 & 12,7 & 12,8 & 13,0 & 13,3 & 14,1 & 14,4 \\
\hline Outros Serviços & 27,0 & 27,1 & 26,9 & 26,7 & 25,1 & 24,7 & 24,5 & 24,3 & 25,5 & 25,3 \\
\hline
\end{tabular}

Fonte: Elaboração própria com base em IBGE (2020a).

Ainda que a constante evolução da queda da produção industrial esteja bastante clara nesse período, é delicado concluir que há um processo de mudança estrutural ou de desindustrialização da economia brasileira de forma cumulativa nos anos 2000 por estes dados. Esse processo de perda da participação da indústria, principalmente a indústria de transformação, fica um pouco mais claro e acentuado a partir de 2008, logo após a crise financeira global de mesmo ano, e do crescimento mais baixo da economia brasileira que vem desde 2014. Desagregando a indústria de transformação, percebe-se que a maior queda de participação vem das indústrias de média-baixa e, principalmente, baixa intensidade tecnológica. Estas últimas, representadas por indústrias tradicionais e intensivas em mão de obra, como alimentos e bebidas, têxtil, vestuário e calçados, vem perdendo competitividade no Brasil diante do aumento da produção e competição asiática nesses tipos de produtos.

Essa evolução da composição do valor agregado pode ser contrastada ao analisar a participação dos setores econômicos nas ocupações totais. A Tabela 2 apresenta esses dados para o mesmo período entre 2000 e 2018. Percebe-se que a participação de trabalhadores na indústria aumentou durante o período. Embora a maior parte deste aumento tenha se dado na construção civil, as indústrias de média-baixa e média-alta IT, que diminuíram suas participações no valor adicionado no período, mantiveram a sua 
participação nas ocupações totais. No entanto, percebe-se que desde 2013 a participação do emprego industrial, que foi de $21,4 \%$, vem caindo. Se era difícil identificar na primeira década do século XXI algum processo de desindustrialização pelos dados de emprego, agora esse processo vem se tornando mais robusto na segunda década, potencializado com a recessão econômica em 2015 e 2016 e a lenta recuperação desde então.

A Tabela 2 ressalta que a grande mudança estrutural em termos de ocupações totais se deu na agropecuária, que possuía uma participação de 21,2\%, em 2000, e passou a apresentar uma participação de apenas 12,8\%, em 2018. Em contrapartida, a maior parte dos empregos migrou para o setor de serviços, que teve um aumento de mais de oito pontos percentuais na participação das ocupações no mesmo período. Ao contrário da indústria, a participação das ocupações nos serviços vem aumentando com a recente crise e o baixo crescimento da economia brasileira. Isso deve estar relacionado com o aumento da taxa de desemprego em 2015 e 2016 e a lenta recuperação deste indicador nos anos mais recentes, bem como do aumento do emprego informal. ${ }^{3}$ Empregos informais típicos, como serviços domésticos, de reparação, de alojamento e alimentação, bem como o processo mais recente de "uberização" do mercado de trabalho, estão classificados em “outros serviços", justamente nas atividades que mais empregaram nos anos 2000.

\section{Tabela 2 - Evolução da participação dos setores econômicos nas ocupações totais, 2000-2018 (em \%)}

\begin{tabular}{|c|c|c|c|c|c|c|c|c|c|c|}
\hline & 2000 & 2002 & 2004 & 2006 & 2008 & 2010 & 2012 & 2014 & 2016 & 2018 \\
\hline Agropecuária & 21,2 & 20,0 & 20,4 & 18,8 & 17,0 & 15,8 & 13,3 & 13,4 & 13,1 & 12,8 \\
\hline Indústria & 18,5 & 18,3 & 18,4 & 18,6 & 19,7 & 20,8 & 21,3 & 20,9 & 19,5 & 18,7 \\
\hline Indústria Extrativa Mineral & 0,2 & 0,2 & 0,3 & 0,2 & 0,3 & 0,3 & 0,3 & 0,3 & 0,2 & 0,2 \\
\hline Indústria de Transformação & 10,5 & 10,3 & 10,8 & 11,1 & 11,6 & 11,8 & 11,8 & 11,3 & 10,6 & 10,5 \\
\hline Baixa IT & 6,7 & 6,5 & 6,8 & 6,9 & 6,9 & 6,9 & 6,9 & 6,6 & 6,3 & 6,3 \\
\hline Média-Baixa IT & 2,0 & 1,9 & 1,9 & 2,0 & 2,2 & 2,3 & 2,3 & 2,3 & 2,0 & 1,9 \\
\hline Média-Alta IT & 1,5 & 1,5 & 1,7 & 1,8 & 2,0 & 2,2 & 2,2 & 2,0 & 1,8 & 1,8 \\
\hline Alta IT & 0,4 & 0,4 & 0,4 & 0,4 & 0,4 & 0,4 & 0,5 & 0,5 & 0,4 & 0,4 \\
\hline SIUP & 0,7 & 0,6 & 0,7 & 0,7 & 0,7 & 0,7 & 0,7 & 0,6 & 0,7 & 0,7 \\
\hline Construção Civil & 7,1 & 7,1 & 6,7 & 6,7 & 7,1 & 8,0 & 8,5 & 8,7 & 8,0 & 7,3 \\
\hline
\end{tabular}

(continua)

3 Depois da mínima histórica de 6,2\% no último trimestre de 2013, a taxa de desemprego chegou a 13,7\% no primeiro trimestre de 2017, caindo somente para $12,7 \%$ no primeiro trimestre de 2019. Ademais, a taxa de informalidade vem crescendo sistematicamente desde 2016, atingindo a máxima de $41,1 \%$ da população ocupada em 2019 (IBGE, 2020b). 
Tabela 2 - Evolução da participação dos setores econômicos nas ocupações totais, 2000-2018 (em \%) (CONTINUAÇÃO)

\begin{tabular}{lcccccccccc}
\hline & $\mathbf{2 0 0 0}$ & $\mathbf{2 0 0 2}$ & $\mathbf{2 0 0 4}$ & $\mathbf{2 0 0 6}$ & $\mathbf{2 0 0 8}$ & $\mathbf{2 0 1 0}$ & $\mathbf{2 0 1 2}$ & $\mathbf{2 0 1 4}$ & $\mathbf{2 0 1 6}$ & $\mathbf{2 0 1 8}$ \\
\hline Serviços & 60,2 & 61,7 & 61,2 & 62,6 & 63,3 & 63,4 & 65,3 & 65,7 & 67,5 & 68,5 \\
\hline Comércio & 17,4 & 18,0 & 17,7 & 18,2 & 17,8 & 18,2 & 18,4 & 18,4 & 18,5 & 18,5 \\
Transporte e Armazenagem & 4,2 & 4,4 & 4,2 & 4,3 & 4,6 & 4,3 & 4,5 & 4,5 & 4,7 & 4,8 \\
Comunicação e Informação & 1,0 & 1,0 & 1,1 & 1,1 & 1,2 & 1,2 & 1,3 & 1,3 & 1,3 & 1,3 \\
Prestados às Empresas & 3,7 & 4,0 & 4,3 & 4,3 & 4,7 & 5,3 & 5,7 & 5,8 & 5,9 & 6,0 \\
Intermediação Financeira & 1,1 & 1,1 & 1,1 & 1,1 & 1,0 & 1,1 & 1,1 & 1,2 & 1,2 & 1,2 \\
Imobiliárias e Aluguéis & 0,4 & 0,4 & 0,4 & 0,4 & 0,3 & 0,4 & 0,4 & 0,4 & 0,4 & 0,4 \\
Outros Serviços & 32,5 & 32,9 & 32,6 & 33,2 & 33,7 & 33,1 & 34,0 & 34,1 & 35,5 & 36,4 \\
\hline
\end{tabular}

Fonte: Elaboração própria com base em IBGE (2020a).

Essas diferenças nos dados setoriais de valor adicionado e ocupações são colocadas em evidências na razão entre as duas variáveis, ou seja, na mensuração da produtividade do trabalho. A Figura 2 apresenta a evolução da taxa de crescimento desse indicador agregado no Brasil entre 2000 e 2018. Apesar do baixo crescimento da mesma em todo o período, foi possível selecionar três momentos distintos de direção da variável: i) estagnação, entre 2000 e 2006; ii) ascensão, entre 2006 e 2013; e iii) queda, entre 2013 e 2018. Esses períodos foram selecionados de acordo com as inflexões da curva de produtividade. Não se pretende colocar esses marcos como mudanças estruturais da economia brasileira, mas como auxílio em um maior nível de detalhamento nas análises a seguir.

\section{Figura 2 - Evolução da taxa de crescimento da produtividade do trabalho agregada} (a preços constantes de 2000), Brasil, 2000-2018 (2000 = 100)

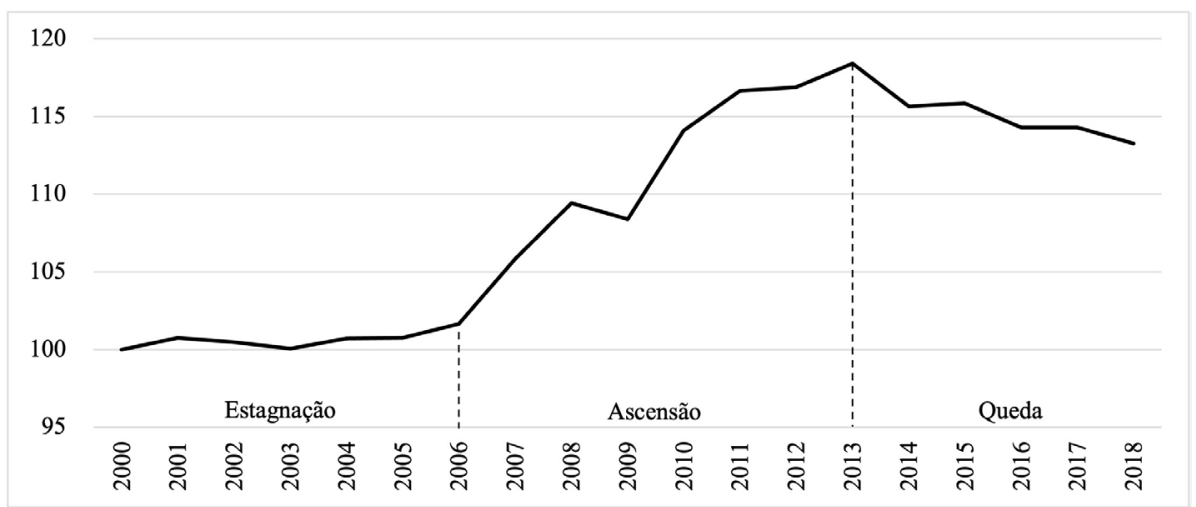


A Tabela 3 apresenta as taxas acumuladas e médias anuais de crescimento da produtividade do trabalho no Brasil. Entre 2000 e 2018, a produtividade do trabalho agregada cresceu $13,26 \%$, ou apenas $0,69 \%$ ao ano em média. Para os subperíodos destacados, há diferenças importantes no período de estagnação (crescimento médio de $0,27 \%$ ), ascensão (crescimento médio de $2,2 \%$ ) e queda (taxa negativa média de $-0,88 \%$ ).

\section{Tabela 3 - Taxas de crescimento acumuladas e médias anuais da produtividade do trabalho (valores constantes a preços de 2000), Brasil, 2000-2018 (em \%)}

\begin{tabular}{|c|c|c|c|c|c|c|c|c|}
\hline & \multicolumn{2}{|c|}{$\begin{array}{c}\text { Geral } \\
(2000-2018)\end{array}$} & \multicolumn{2}{|c|}{$\begin{array}{r}\text { Estagnação } \\
(2000-2006)\end{array}$} & \multicolumn{2}{|c|}{$\begin{array}{c}\text { Ascensão } \\
(2006-2013)\end{array}$} & \multicolumn{2}{|c|}{$\begin{array}{c}\text { Queda } \\
(2013-2018)\end{array}$} \\
\hline & Acum. & Anual & Acum. & Anual & Acum. & Anual & Acum. & Anual \\
\hline Total & 13,6 & 0,69 & 1,65 & 0,27 & 16,48 & 2,20 & $-4,34$ & $-0,88$ \\
\hline Agropecuária & 140,56 & 5,00 & 27,11 & 4,08 & 61,77 & 7,11 & 16,99 & 3,19 \\
\hline Indústria & $-5,32$ & $-0,30$ & $-2,26$ & $-0,38$ & $-3,28$ & $-0,48$ & 0,15 & 0,03 \\
\hline Indústria Extrativa Mineral & 65,93 & 2,85 & 23,25 & 3,54 & $-15,26$ & $-2,34$ & 58,87 & 9,70 \\
\hline Indústria de Transformação & $-12,21$ & $-0,72$ & $-4,25$ & $-0,72$ & $-4,15$ & $-0,60$ & $-4,35$ & $-0,89$ \\
\hline Baixa IT & $-15,20$ & $-0,91$ & $-7,45$ & $-1,28$ & $-6,56$ & $-0,96$ & $-1,94$ & $-0,39$ \\
\hline Média-Baixa IT & $-27,92$ & $-1,80$ & $-4,20$ & $-0,71$ & $-19,89$ & $-3,12$ & $-6,08$ & $-1,25$ \\
\hline Média-Alta IT & $-22,40$ & $-1,40$ & $-10,60$ & $-1,85$ & $-6,40$ & $-0,94$ & $-7,25$ & $-1,49$ \\
\hline Alta IT & 48,34 & 2,21 & 0,42 & 0,07 & 14,16 & 1,91 & 29,39 & 5,29 \\
\hline SIUP & $-14,66$ & $-0,88$ & $-1,16$ & $-0,19$ & 1,65 & 0,23 & $-18,40$ & $-3,99$ \\
\hline Construção Civil & 14,21 & 0,74 & $-8,21$ & $-1,42$ & 13,95 & 1,88 & 13,68 & 2,6 \\
\hline Serviços & 3,72 & 0,20 & $-1,66$ & $-0,28$ & 13,71 & 1,85 & $-7,24$ & $-1,49$ \\
\hline Comércio & 1,96 & 0,11 & $-5,51$ & $-0,94$ & 22,35 & 2,92 & $-11,81$ & $-2,48$ \\
\hline Transporte e Armazenagem & $-6,97$ & $-0,40$ & $-5,96$ & $-1,02$ & 12,81 & 1,74 & $-12,31$ & $-2,59$ \\
\hline Comunicação e Informação & 14,51 & 0,76 & $-6,46$ & $-1,11$ & 16,57 & 2,21 & 5,02 & 0,98 \\
\hline Prestados às Empresas & $-25,27$ & $-1,61$ & $-13,85$ & $-2,45$ & $-4,98$ & $-0,73$ & $-8,71$ & $-1,81$ \\
\hline Intermediação Financeira & 39,92 & 1,88 & 9,08 & 1,46 & 49,48 & 5,91 & $-14,19$ & $-3,02$ \\
\hline Imobiliárias e Aluguéis & 17,74 & 0,91 & 21,86 & 3,35 & 9,34 & 1,28 & $-11,63$ & $-2,44$ \\
\hline Outros Serviços & $-5,07$ & $-0,29$ & 0,51 & 0,08 & 5,36 & 0,75 & $-5,56$ & $-1,14$ \\
\hline
\end{tabular}

Fonte: Elaboração própria com base em IBGE (2020a).

Quando a produtividade do trabalho é desagregada, verifica-se pela Tabela 3 o fraco desempenho da indústria, especialmente a indústria de transformação, com taxas negativas em todos os períodos. Mesmo no período de ascensão (2006-2013), verifica-se que a indústria obteve um mau resultado em termos de produtividade, o que mostra que o aumento do emprego industrial nesse período (Tabela 2) não foi acompanhado por uma melhor eficiência produtiva. Até mesmo o bom desempenho 
geral da indústria extrativa mineral apresentou uma evolução ruim no período de ascensão (-2,34\% em média), voltando a ter um bom desempenho no período de queda (9,7\% em média). Somente a indústria de alta IT apresentou evolução positiva da produtividade em todos os períodos.

Por outro lado, a agropecuária apresentou o maior crescimento médio da produtividade do trabalho nos anos 2000 (5\%). Este setor conseguiu aumentar de maneira significativa o seu valor adicionado aliado a uma grande queda do número de ocupações. Já o setor de serviços apresentou um crescimento modesto da produtividade do trabalho, com destaque negativo para os serviços prestados às empresas $(-1,61 \%$ em média) e transporte e armazenagem (-0,4\% me média). Esses dados mostram que até mesmo os setores mais relacionados à indústria e ao processo produtivo apresentaram taxas negativas de crescimento da produtividade.

Outro destaque negativo foi o setor de serviços em 2013-2018. Se neste período a indústria obteve um crescimento de praticamente zero (segurado pela indústria extrativa mineral) e a agropecuária continuou a ter um bom desempenho, os serviços puxaram em grande parte o resultado negativo da economia. Isso deve estar relacionado com o aumento do emprego na área de serviços neste período (Tabela 2), inclusive do emprego informal, que geralmente são representados por empregos menos produtivos.

Apesar dessa evolução distinta da produtividade do trabalho entre os setores econômicos no Brasil entre 2000 e 2018, não se pode afirmar ainda que a agropecuária foi a principal responsável pelo crescimento da produtividade do trabalho de toda a economia neste período. Isso ocorre, pois, a contribuição de cada uma das atividades econômicas para o crescimento da produtividade agregada depende, entre outros fatores, do peso de cada setor na estrutura produtiva, fator que será tratado na próxima seção.

\section{DECOMPOSIÇÃO DA PRODUTIVIDADE AGREGADA NO BRASIL (2000-2018)}

A Tabela 4 apresenta os resultados dos termos da equação (6) para o período geral (2000-2018). A primeira coluna mostra a contribuição de cada atividade econômica para o crescimento da produtividade agregada. A soma das contribuições de cada setor equivale ao crescimento da produtividade total, que neste caso é 13,26\%. As outras quatro colunas são referentes aos efeitos eficiência intrassetorial, composição e preço apresentados na equação (6), e ao efeito especialização dinâmica ilustrado no Quadro 1. A soma dos três primeiros efeitos para cada atividade equivale ao valor de contribuição.

Entre 2000 e 2018, o setor que mais contribuiu para o crescimento da produtividade da economia brasileira foi o de serviços (14,96\% de um total de 13,26\%). Essa contribuição maior do que a taxa total foi em decorrência de outros setores contribuírem negativamente, 
como a indústria com -2,01\%. A agropecuária, por outro lado, por mais que apresentasse uma taxa de crescimento da produtividade de 140,56\% (Tabela 3), contribuiu apenas com $0,31 \%$ para a produtividade agregada. Isso ocorre devido ao cálculo de decomposição levar em consideração a participação dos setores no valor adicionado. Dentro dos serviços, as maiores contribuições vieram dos segmentos menos intensivos em tecnologia, sobretudo o comércio e "outros serviços”. Todos os grupos setoriais ligados a indústria de transformação contribuíram negativamente para a produtividade agregada. Isso mostra que muito do baixo desempenho da economia brasileira nos anos 2000 decorre da perda de eficiência da indústria nesses anos.

\section{Tabela 4 - Decomposição do crescimento da produtividade do trabalho, Brasil, 2000-2018 (em \%)}

\begin{tabular}{|c|c|c|c|c|c|}
\hline & $\begin{array}{c}\text { Contribuição } \\
\text { ao crescimento }\end{array}$ & $\begin{array}{c}\text { Eficiência } \\
\text { Intrassetorial }\end{array}$ & Composição & Preço & $\begin{array}{c}\text { Especialização } \\
\text { Dinâmica }\end{array}$ \\
\hline Total & 13,26 & 4,92 & 8,04 & 0,29 & Bônus + \\
\hline Agropecuária & 0,31 & 5,45 & $-3,15$ & $-1,99$ & Ônus + \\
\hline Indústria & $-2,01$ & $-1,93$ & 0,50 & $-0,58$ & Ônus - \\
\hline Indústria Extrativa Mineral & 1,66 & 1,06 & $-0,16$ & 0,75 & Ônus + \\
\hline Indústria de Transformação & $-1,38$ & $-2,51$ & 0,40 & 0,73 & Ônus - \\
\hline Baixa IT & $-0,53$ & $-0,92$ & $-0,29$ & 0,68 & Bônus - \\
\hline Média-Baixa IT & $-0,07$ & $-1,21$ & $-0,05$ & 1,19 & Bônus - \\
\hline Média-Alta IT & $-0,51$ & $-0,99$ & 0,70 & $-0,22$ & Ônus - \\
\hline Alta IT & $-0,26$ & 0,61 & 0,04 & $-0,92$ & Bônus + \\
\hline SIUP & $-2,38$ & $-0,91$ & 0,17 & $-1,64$ & Ônus - \\
\hline Construção Civil & 0,09 & 0,42 & 0,09 & $-0,42$ & Bônus + \\
\hline Serviços & 14,96 & 1,41 & 10,69 & 2,86 & Bônus + \\
\hline Comércio & 6,64 & 0,22 & 0,69 & 5,73 & Bônus + \\
\hline Transporte e Armazenagem & 1,31 & $-0,31$ & 0,60 & 1,03 & Ônus - \\
\hline Comunicação e Informação & $-0,40$ & 0,57 & 1,12 & $-2,08$ & Bônus + \\
\hline Prestados às Empresas & 1,86 & $-1,96$ & 3,10 & 0,72 & Ônus - \\
\hline Intermediação Financeira & 1,13 & 2,50 & 0,37 & $-1,75$ & Bônus + \\
\hline Imobiliárias e Aluguéis & $-1,15$ & 1,93 & 1,44 & $-4,52$ & Bônus + \\
\hline Outros Serviços & 5,56 & $-1,55$ & 3,38 & 3,72 & Ônus - \\
\hline
\end{tabular}

Fonte: Elaboração própria com base em IBGE (2020a).

Quanto aos efeitos do lado direito da Tabela 4, verifica-se que a taxa de crescimento da produtividade do trabalho total de $13,26 \%$ teve como contribuição $4,92 \%$ de efeito eficiência intrassetorial, ou seja, pelo crescimento da produtividade dentro de cada um dos setores econômicos, 8,04\% de efeito composição, ou seja, da migração 
de mão de obra para setores que mais cresceram a produtividade, e 0,29\% de efeito preço, ou seja, de uma pequena mudança dos preços relativos favoráveis à economia. Dessa maneira, percebe-se o efeito importante e maior da mudança estrutural sobre a produtividade agregada. Como os sinais dos efeitos eficiência intrassetorial e composição são positivos, tem-se um efeito especialização dinâmica de bônus estrutural eficiente (Bônus +), no qual a mudança estrutural na economia brasileira nesse período se deu por realocação do trabalho para atividades que mais cresceram a sua produtividade.

Pela Tabela 4 fica claro que a migração do trabalho para atividades que mais cresceram a sua produtividade se deu nos serviços, que teve efeito composição (10,69\%) maior do que no total da economia (8,04\%) e efeito eficiência intrassetorial positivo de $1,41 \%$. Dentro dos serviços, destaca-se o efeito de bônus estrutural eficiente de intermediação financeira e imobiliários e aluguéis. Já os serviços de comunicação e informação, transporte e armazenagem e "outros" tiveram efeito de ônus estrutural ineficiente (Ônus -), ou seja, aumentaram a sua participação com quedas da produtividade.

Outra característica marcante dos serviços é a de que as maiores contribuições vindas do comércio $(6,64 \%)$ e de "outros serviços" $(5,56 \%)$ se deu principalmente via mudanças favoráveis de preços relativos, ou seja, as suas contribuições se deram menos via eficiência e mais via preços. Este efeito é similar ao raciocínio de doenças de custos dos serviços de Baumol, Blackman e Wolff (1985), principalmente no que se refere a "outros serviços" composto por atividades de baixa produtividade e baixos ganhos de escala com consequente aumento de preços. No entanto, este efeito também foi visto em atividades empresariais e que estão ligados a manufatura, como transporte e comunicação e informação, o que auxilia no baixo desempenho da indústria.

A Tabela 4 ressalta também que o efeito da indústria sobre a produtividade agregada foi de ônus estrutural ineficiente, dado o efeito eficiência intrasetorial negativo (-1,93\%) e o efeito composição positivo (0,5\%). Como a Tabela 2 mostrou, o emprego industrial aumentou durante todo o período, apesar da queda mais recente a partir de 2013. Dentre os destaques negativos de indústrias que aumentaram a sua participação no emprego reduzindo sua eficiência estão os grupos de média-alta IT e construção civil. Já as indústrias de baixa e média-baixa IT obtiveram efeito de bônus estrutural ineficiente, pois há perda de participação ao mesmo tempo em que caiu a produtividade, enquanto a indústria extrativa mineral obteve efeito de ônus estrutural eficiente, em movimento semelhante ao destacado por Fagerberg (2000) de perda de participação via aumento da eficiência. Pelo lado positivo, tem-se o efeito de bônus estrutural eficiente da indústria de alta IT e SIUP. No entanto, mesmo para estas a contribuição na economia é negativa ou quase zero devido ao efeito preço relativo desfavorável. O resultado é que com exceção da indústria extrativa mineral, que possui uma participação baixa na economia brasileira, 
a contribuição da indústria para a produtividade agregada foi negativa, principalmente devido a sua baixa eficiência intrassetorial.

Cabe destacar, por fim, o alto desempenho intrassetorial da agropecuária $(5,45 \%$ de $4,92 \%$ de toda economia). Acontece que o grande efeito negativo de composição $(-3,15 \%)$ e preço $(-1,99 \%)$, bem como a baixa participação no valor adicionado da economia, praticamente anularam a contribuição desse setor para a produtividade agregada (apenas $0,31 \%$ ). Isso mostra que por mais eficiente que a agropecuária tenha se apresentado nos últimos anos, ela não é capaz de influenciar o crescimento de longo prazo da economia brasileira.

Dessa maneira, pode-se concluir que o baixo crescimento da produtividade do trabalho agregada para o período geral 2000-2018 parece ter menos a ver com um possível processo de desindustrialização e mais a ver com uma perda de eficiência produtiva da indústria e de alguns serviços. Isso ocorre pelos efeitos eficiência negativos dos setores industriais da manufatura e de alguns serviços, e pelos efeitos composição positivos dos mesmos, indicando que houve aumento da participação no emprego. De forma agregada, o aumento da produtividade e de trabalhadores nos serviços explicam o bônus estrutural da economia brasileira nesse período.

As mudanças de direções da produtividade agregada destacadas pela Figura 2 podem mostrar, no entanto, algumas diferenças e tendências setoriais para a produtividade agregada. A Tabela 5 mostra a decomposição da equação (6) para os três subperíodos destacados: estagnação, 2000-2006; ascensão, 2006-2013; e queda, 2013-2018.

Tabela 5 - Decomposição do crescimento da produtividade do trabalho, Brasil, subperíodos (em \%)

\begin{tabular}{lccccc}
\hline & $\begin{array}{c}\text { Contribuição } \\
\text { ao crescimento }\end{array}$ & $\begin{array}{c}\text { Eficiência } \\
\text { Intrassetorial }\end{array}$ & Composição & Preço & $\begin{array}{c}\text { Especialização } \\
\text { Dinâmica }\end{array}$ \\
\hline Total & $2000-2006$ & & \\
\hline Agropecuária & 1,65 & 0,53 & 1,06 & 0,06 & Bônus + \\
\hline Indústria & $-0,30$ & 1,30 & $-0,67$ & $-0,94$ & Ônus + \\
\hline Indústria Extrativa Mineral & 1,39 & $-1,14$ & 0,80 & 1,72 & Ônus - \\
Indústria de Transformação & 2,19 & 0,50 & $-0,03$ & 1,72 & Ônus + \\
Baixa IT & 1,59 & $-1,12$ & 1,26 & 1,44 & Ônus - \\
Média-Baixa IT & $-0,32$ & $-0,44$ & 0,14 & $-0,02$ & Ônus - \\
Média-Alta IT & 0,89 & $-0,18$ & 0,10 & 0,97 & Ônus - \\
Alta IT & 0,72 & $-0,50$ & 0,80 & 0,43 & Ônus - \\
Construção Civil & 0,30 & 0,01 & 0,23 & 0,07 & Bônus + \\
SIUP & $-2,54$ & $-0,48$ & $-0,34$ & $-1,71$ & Bônus - \\
\hline
\end{tabular}


Tabela 5 - Decomposição do crescimento da produtividade do trabalho, Brasil, subperíodos (em \%) (CONTINUAÇÃO)

\begin{tabular}{|c|c|c|c|c|c|}
\hline & $\begin{array}{c}\text { Contribuição } \\
\text { ao crescimento }\end{array}$ & $\begin{array}{c}\text { Eficiência } \\
\text { Intrassetorial }\end{array}$ & Composição & Preço & $\begin{array}{c}\text { Especialização } \\
\text { Dinâmica }\end{array}$ \\
\hline Serviços & 0,56 & 0,36 & 0,92 & $-0,73$ & Ônus - \\
\hline Comércio & 3,23 & $-0,55$ & 0,47 & 3,32 & Ônus - \\
\hline Transporte e Armazenagem & $-0,17$ & $-0,22$ & 0,09 & $-0,04$ & Ônus - \\
\hline Comunicação e Informação & 0,13 & $-0,29$ & 0,66 & $-0,24$ & Ônus - \\
\hline Prestados às Empresas & 0,23 & $-0,86$ & 0,78 & 0,32 & Ônus - \\
\hline Intermediação Financeira & 0,48 & 0,62 & $-0,46$ & 0,33 & Ônus + \\
\hline Imobiliárias e Aluguéis & $-3,16$ & 2,14 & $-1,26$ & $-4,03$ & Ônus + \\
\hline Outros Serviços & $-0,19$ & $-0,46$ & 0,65 & $-0,38$ & Ônus - \\
\hline \multicolumn{6}{|c|}{$2006-2013$} \\
\hline Total & 16,48 & 9,60 & 6,96 & $-0,07$ & Bônus + \\
\hline Agropecuária & 1,01 & 2,77 & $-2,09$ & 0,33 & Ônus + \\
\hline Indústria & 1,26 & $-1,13$ & 4,41 & $-2,01$ & Ônus - \\
\hline Indústria Extrativa Mineral & 1,33 & $-0,70$ & 0,99 & 1,04 & Ônus - \\
\hline Indústria de Transformação & $-2,30$ & $-1,23$ & 1,63 & $-2,70$ & Ônus - \\
\hline Baixa IT & 0,20 & $-0,38$ & 0,00 & 0,58 & Bônus - \\
\hline Média-Baixa IT & $-1,90$ & $-0,78$ & 0,50 & $-1,62$ & Ônus - \\
\hline Média-Alta IT & $-0,24$ & $-0,31$ & 0,86 & $-0,79$ & Ônus - \\
\hline Alta IT & $-0,36$ & 0,23 & 0,27 & $-0,86$ & Bônus + \\
\hline Construção Civil & 3,09 & 0,75 & 1,46 & 0,88 & Bônus + \\
\hline SIUP & $-0,86$ & 0,05 & 0,33 & $-1,24$ & Bônus + \\
\hline Serviços & 14,21 & 7,96 & 4,64 & 1,61 & Bônus + \\
\hline Comércio & 4,55 & 2,68 & $-0,07$ & 1,94 & Ônus + \\
\hline Transporte e Armazenagem & 1,76 & 0,52 & 0,23 & 1,01 & Bônus + \\
\hline Comunicação e Informação & $-0,31$ & 0,65 & 0,54 & $-1,50$ & Bônus + \\
\hline Prestados às Empresas & 2,17 & $-0,35$ & 2,07 & 0,45 & Ônus - \\
\hline Intermediação Financeira & $-0,22$ & 2,94 & 0,24 & $-3,41$ & Bônus + \\
\hline Imobiliárias e Aluguéis & 1,79 & 0,88 & 0,80 & 0,12 & Bônus + \\
\hline Outros Serviços & 4,48 & 0,64 & 0,83 & 3,00 & Bônus + \\
\hline \multicolumn{6}{|c|}{$2013-2018$} \\
\hline Total & $-4,34$ & $-4,77$ & 0,36 & 0,07 & Ônus - \\
\hline Agropecuária & $-0,35$ & 0,81 & $-0,12$ & $-1,04$ & Ônus + \\
\hline Indústria & $-3,95$ & 0,73 & $-3,78$ & $-0,90$ & Ônus + \\
\hline Indústria Extrativa Mineral & $-1,60$ & 1,65 & $-1,03$ & $-2,21$ & Ônus + \\
\hline Indústria de Transformação & $-0,53$ & $-0,20$ & $-1,79$ & 1,45 & Bônus - \\
\hline Baixa IT & $-0,35$ & $-0,09$ & $-0,36$ & 0,10 & Bônus - \\
\hline Média-Baixa IT & 0,82 & $-0,17$ & $-0,48$ & 1,47 & Bônus - \\
\hline Média-Alta IT & $-0,83$ & $-0,26$ & $-0,63$ & 0,06 & Bônus - \\
\hline Alta IT & $-0,17$ & 0,32 & $-0,32$ & $-0,18$ & Ônus + \\
\hline SIUP & $-2,51$ & $-1,02$ & $-0,82$ & $-0,67$ & Bônus - \\
\hline Construção Civil & 0,69 & 0,30 & $-0,15$ & 0,53 & Ônus + \\
\hline
\end{tabular}

(continua) 


\section{Tabela 5 - Decomposição do crescimento da produtividade do trabalho, Brasil, subperíodos (em \%) (CONTINUAÇÃO)}

\begin{tabular}{lccccc}
\hline & $\begin{array}{c}\text { Contribuição } \\
\text { ao crescimento }\end{array}$ & $\begin{array}{c}\text { Eficiência } \\
\text { Intrassetorial }\end{array}$ & Composição & Preço & $\begin{array}{c}\text { Especialização } \\
\text { Dinâmica }\end{array}$ \\
\hline Serviços & $-0,04$ & $-6,31$ & 4,26 & 2,01 & Ônus - \\
\hline Comércio & $-1,02$ & $-1,63$ & 0,24 & 0,37 & Ônus - \\
Transporte e Armazenagem & $-0,26$ & $-0,57$ & 0,25 & 0,06 & Ônus - \\
Comunicação e Informação & $-0,18$ & 0,7 & $-0,04$ & $-0,30$ & Ônus + \\
Prestados às Empresas & $-0,49$ & $-0,60$ & 0,19 & $-0,08$ & Ônus - \\
Intermediação Financeira & 0,74 & $-0,98$ & 0,52 & 1,20 & Ônus - \\
Imobiliárias e Aluguéis & 0,15 & $-1,15$ & 1,46 & $-0,16$ & Ônus - \\
Outros Serviços & 1,01 & $-1,54$ & 1,64 & 0,92 & Ônus - \\
\hline
\end{tabular}

Fonte: Elaboração própria com base em IBGE (2020a).

Para o primeiro subperíodo (2000-2006), percebe-se que a maior contribuição para o crescimento da produtividade agregada (1,65\%) se deu na indústria (contribuição de $1,39 \%$ ), enquanto a agropecuária contribuiu negativamente devido a sua menor composição e piora nos preços relativos. Quando se abre os efeitos da decomposição, percebe-se que a maior contribuição se deu por meio da indústria extrativa mineral e de transformação, e isso ocorreu muito mais devido à melhora nos preços relativos do que por eficiência intrassetorial. Esse movimento é explicado pelo aumento dos preços das commodities minerais e de combustíveis fósseis nesse período, ${ }^{4}$ puxando o crescimento da indústria extrativa. Essa observação é sintetizada pelo efeito ônus estrutural ineficiente da indústria, ressaltando que a contribuição positiva sobre a produtividade agregada se deu via preços. Neste período, os serviços contribuíram pouco para a produtividade agregada.

Para o segundo subperíodo (2006-2011), a dinâmica das contribuições setoriais sobre a produtividade agregada muda completamente, com uma característica semelhante ao mostrado pelo período geral da Tabela 4. Nesta fase de maior crescimento da produtividade agregada (16,48\%), os serviços passam a ganhar importância (contribuição de $14,21 \%)$, principalmente devido ao seu efeito eficiência intrassetorial positivo (7,96\%). Há um bônus estrutural claro na economia devido a migração de trabalhadores para as atividades de serviços que cresceram a sua produtividade. A indústria de transformação, por outro lado, passa a ter uma piora nos preços relativos, que, junto com a ineficiência

4 Segundo dados da Unctad (2020), os preços dos minerais, minérios, metais e petróleo bruto cresceram $275 \%$ entre 2000 e 2011, caracterizando um movimento de boom das commodities. No entanto, os preços passaram a cair mais sistematicamente após 2011. Entre 2011 e 2016, a queda de preços desses produtos foi de $45 \%$. 
intrassetorial, contribuíram negativamente para a produtividade agregada. A exceção se dá pelas indústrias de alta IT, construção civil e SIUP. Neste período também não se observa sinais fortes de desindustrialização, pois há aumento do emprego industrial com efeito composição positivo (4,41\%).

Por fim, para o terceiro subperíodo (2013-2018), tem-se pela primeira vez nos anos 2000 efeito ônus estrutural para toda a economia, sinalizando que a mudança estrutural, ao contrário dos dois subperíodos anteriores, contribuiu para a queda da produtividade agregada $(-4,34 \%)$. Isso se deu em grande parte por meio do ônus estrutural ineficiente dos serviços, com grande ineficiência intrassetorial (-6,31\%) diante de alto efeito composição (4,26\%). Ao contrário dos outros subperíodos, a soma dos serviços contribuiu negativamente para a produtividade agregada entre 2013 e 2018. Neste caso, como já ressaltado, o aumento do emprego informal deve ter contribuído para a baixa produtividade deste setor.

Já a indústria contribuiu negativamente para a produtividade agregada $(-3,95 \%)$, em 2013-2018, via queda na composição (-3,78\%) e piora nos preços relativos $(-0,9 \%)$. Por outro lado, verifica-se que o efeito eficiência intrassetorial da indústria não é mais negativo, embora baixo (0,73\%). Isso só ocorreu devido ao ótimo desempenho eficiência da indústria extrativa mineral e, em menor proporção, ao grupo de alta IT e SIUP. A indústria extrativa só não contribuiu positivamente para a produtividade agregada devido ao seu alto efeito preço negativo $(-2,21 \%)$, sinalizando a queda nos preços das commodities depois de seu boom na primeira década nos anos 2000. A maior parte da indústria de transformação continuou apresentando efeitos eficiência negativos. O que muda é o efeito composição, que agora sim evidencia uma contribuição negativa para todos os grupos industriais, indicando que há um movimento mais recente de mudança estrutural desindustrializadora.

Conclui-se, assim, alguns movimentos gerais da composição da produtividade agregada no Brasil entre 2000 e 2018: i) grande influência via preços da indústria extrativa mineral em 2000-2006; ii) grande influência dos serviços com bônus estrutural em 2006-2013; e iii) perda da eficiência dos serviços e desindustrialização com ônus estrutural em 2013-2018. Com exceção da indústria de alta IT, que é pouco representativa na estrutura da economia brasileira, em todos os períodos pôde-se ver baixa eficiência intrassetorial da indústria de transformação.

\section{CONSIDERAÇÕES FINAIS}

Este artigo apresentou a evolução da estrutura produtiva e de empregos, e uma análise de decomposição da produtividade do trabalho no Brasil entre 2000 e 2018. Em nível 
agregado, verifica-se que a economia brasileira apresentou um crescimento baixo da produtividade do trabalho nos anos 2000, com uma taxa média anual de crescimento de apenas $0,69 \%$ e que vem caindo e apresentando taxas negativas nos anos mais recentes. Diante da necessidade de aumentar a eficiência produtiva ou a produtividade para o crescimento econômico de longo prazo do país, este artigo procurou esclarecer qual foi o efeito da mudança estrutural sobre o baixo desempenho da produtividade no Brasil nos anos 2000. Especialmente, buscou-se analisar se um possível processo de desindustrialização está relacionado com o fraco desempenho da economia brasileira nesse período. As principais conclusões são pontuadas a seguir.

Em primeiro lugar, a estrutura produtiva brasileira se manteve relativamente estável entre 2000 e 2018, com mudanças mais significativas em: i) maior participação produtiva da agropecuária e dos serviços em detrimento da indústria; e ii) maior queda das ocupações na agropecuária vis-à-vis um aumento das ocupações nos serviços. Esses movimentos são mais intensos após o ano de 2013, quando a economia brasileira começa a dar sinais de uma crise de crescimento que perdura até hoje.

Em segundo lugar, em nível setorial, as atividades que apresentaram as maiores taxas de crescimento da produtividade foram a agropecuária e a indústria extrativa mineral, evidenciando a especialização em bens básicos da economia brasileira, com taxas negativas da indústria de transformação e taxas baixas dos serviços.

Em terceiro lugar, devido à grande participação dos serviços na estrutura produtiva brasileira, estes apresentaram a maior contribuição ao crescimento da produtividade da economia. Observa-se, porém, que são os serviços menos intensivos em tecnologia e mais ligados à demanda final, como comércio e "outros serviços", que mais contribuíram para este crescimento via aumento da participação no trabalho e dos preços relativos. A característica destes tipos de serviços pode estar associada ao efeito de doenças de custos de Baumol, Blackman e Wolff (1985), pois são os serviços gerais menos intensivos em tecnologia e que possuem a maior participação no emprego e no valor adicionado na economia brasileira.

Em quarto lugar, ao analisar a decomposição da produtividade do trabalho agregada entre 2000 e 2018, percebe-se que o efeito eficiência da produtividade da indústria é negativo e o efeito composição é positivo, evidenciando uma especialização de ônus estrutural ineficiente. $\mathrm{O}$ emprego industrial só passa a apresentar quedas a partir de 2013, indicando de forma mais clara um processo de desindustrialização em meio a uma crise de crescimento mais aguda da economia brasileira.

Conclui-se, assim, que o baixo crescimento da produtividade do trabalho agregada entre 2000 e 2018 parece ter menos a ver com uma possível mudança estrutural via desindustrialização e mais a ver com uma perda de eficiência produtiva da indústria e de alguns serviços mais intensivos em tecnologia, como comunicação e informação. 
Isso é explicado pela manutenção do emprego nesses setores pelo menos até 2013, ao mesmo tempo que contribuíram negativamente para o crescimento da produtividade agregada. No entanto, a partir de 2013, o início de uma mudança estrutural em decorrência de um processo de desindustrialização da manufatura parece atingir negativamente a produtividade do trabalho da economia brasileira. Aliada a isso, o crescimento relativo do emprego e provavelmente da informalidade nos serviços de menor intensidade tecnológica auxiliaram ainda mais a baixa eficiência, e, consequentemente, o baixo crescimento econômico dos últimos anos.

$\mathrm{O}$ artigo contribui para o debate sobre o crescimento da produtividade e desindustrialização no Brasil ao aplicar um método de decomposição que leve em consideração as mudanças nos preços relativos em uma base de dados mais recente e longa da economia. Em comparação com a literatura internacional destacada na seção 1 (TIMMER; VRIES, 2009), a economia brasileira nos anos 2000 possui resultados semelhantes no que diz respeito às maiores contribuições dos serviços para a produtividade agregada. Isso ocorre devido ao fato estilizado de o setor terciário apresentar maior participação e crescimento na maioria dos países avançados e na América Latina nas últimas décadas. No entanto, a economia brasileira se difere por ter apresentado um significativo efeito de bônus estrutural devido a migração das ocupações para os serviços, vindos principalmente da agropecuária.

Até 2013, o efeito bônus estrutural via serviços contribuiu para o crescimento da produtividade agregada, conseguindo contrabalancear o crescimento negativo da indústria. Já a partir de 2013, os serviços passaram a apresentar contribuições negativas à produtividade agregada devido ao significativo aumento das ocupações em serviços de baixa intensidade tecnológica, bem como uma tendência de queda mais significativa do emprego industrial. Estes aspectos se assemelham ao ônus estrutural observado na economia mexicana recente por Padilha-Pérez e Villarreal (2017), e na análise de especialização regressiva estrutural de McMillan, Rodrik e Verduzco-Gallo (2014) para os países africanos e latino-americanos nas últimas décadas.

Já os estudos brasileiros que aplicaram técnicas de shift-share, como Squeff e De Negri (2014) e Jacinto Ribeiro (2015), se concentraram na primeira década dos anos 2000, no qual, assim como neste estudo, é possível ver a grande contribuição dos serviços para a produtividade agregada. No entanto, uma maior desagregação neste artigo mostra que os serviços que mais contribuíram para essa produtividade são os mais básicos e menos intensivos em tecnologia. Jacinto e Ribeiro (2015) também mostravam que não havia sinais de doenças de custos na economia brasileira entre 2002 e 2009, enquanto este artigo mostra que pelo menos no período mais recente (2013-2018) há sim indícios de doenças de custos no Brasil devido à queda na produtividade dos serviços aliada ao aumento nos seus preços relativos. 
Quanto à indústria, o artigo corrobora com o efeito de ônus estrutural da manufatura apresentado por Rocha (2007) entre 1970 e 2001 . Apesar de o autor fazer uma análise de decomposição apenas da indústria e sem levar em consideração os efeitos de preços relativos, observa-se a profunda perda de eficiência da indústria de transformação da economia brasileira como uma questão estrutural e de longo prazo. A diferença é que, enquanto a discussão em Rocha (2007) era sobre a especialização em setores industriais de menor conteúdo tecnológico, verifica-se que nos anos 2000 a perda de contribuição para a produtividade agregada é ainda maior nos setores industriais de baixa intensidade tecnológica. Neste caso, o problema é que a migração das ocupações não está indo para atividades de maior crescimento da produtividade ou de maior conteúdo tecnológico, e sim para serviços básicos geralmente informais e de baixa produtividade.

Por fim, ressalta-se como limitação do estudo e oportunidade para próximas pesquisas outras maneiras de mensuração da produtividade que contemplem a interdependência setorial. Este pode ser o caso de análises utilizando matrizes insumo-produto apresentadas por De Juan e Febrero (2000), buscando-se observar as contribuições intersetoriais para a produtividade da economia.

\section{REFERÊNCIAS}

AVILLEZ, R. Sectoral contributions to labour productivity growth in Canada: does the choice of decomposition formula matter? International Productivity Monitor, n. 24, p. 97-117, 2012.

BADRIAH, L. S.; ALISJAHBANA, A. S.; WIBOWO, K.; HADIYANTO, F. Labour productivity growth in the industrial sector of Indonesia: Structural bonus or structural burden? Malaysian Journal of Economic Studies, v. 56, n. 1, p. 139-159, 2019.

BAUMOL, W. J. Macroeconomics of unbalanced growth: The anatomy of urban crisis. American Economic Review, v. 57, n. 3, p. 415-426, 1967.

BAUMOL, W. J.; BLACKMAN, S. A. B.; WOLFF, E. N. Unbalanced growth revisited: Asymptotic stagnancy and new evidence. American Economic Review, v. 75, n. 4, p. 806-817, 1985.

BRONDINO, G. Productivity growth and structural change in China (1995-2009): A subsystems analysis. Structural Change and Economic Dynamics, v. 49, p. 183-191, 2019

CARREE, M. A. Technological progress, structural change and productivity growth: A comment. Structural Change and Economic Dynamics, v. 14, n. 1, p. 109-115, 2003.

CAVALCANTE, L. R. Classificações tecnológicas: uma sistematização. Brasília: IPEA, 2014. [Nota Técnica n. 17]

CHEN, S.; JEFFERSON, G. H.; ZHANG, J. Structural change, productivity growth and industrial transformation in China. China Economic Review, v. 22, n. 1, p. 133-150, 2011.

CHENERY, H. Growth and transformation. In: CHENERY, H.; ROBINSON, S.; SYRQUIN, M. (Orgs.). Industrialization and growth: A comparative study. Oxford: Oxford University Press, 1986, p. 13-36. 
DE JUAN, O.; FEBRERO, E. Measuring productivity from vertically integrated sectors. Economic Systems Research, v. 12, n. 1, p. 65-82, 2000.

DE NEGRI, F.; CAVALCANTE, L. R. Produtividade no Brasil: desempenho e determinantes. Brasília: IPEA, 2014.

DIEWERT, W. E. Decomposition of productivity growth into sectoral effects. Journal of Productivity Analysis, v. 43, n. 3, p. 367-387, 2015.

DIAO, X.; KWEKA, J.; MCMILLAN, M. Small firms, structural change and labor productivity growth in Africa: Evidence from Tanzania. World Development, v. 105, p. 400-415, 2018.

FAGERBERG, J. Technological progress, structural change and productivity growth: a comparative study. Structural Change and Economic Dynamics, v. 11, n. 4, p. 393-411, 2000.

FISHER, A. G. B. Production, primary, secondary and tertiary. The Economic Record, v. 15, n. 1, p.24-38, 1939.

IBGE - INSTITUTO BRASILEIRO DE ESTATÍSTICA E GEOGRAFIA. Sistema de contas nacionais: Brasil 2018. Rio de Janeiro: IBGE, 2020a. Disponível em: https://www.ibge.gov.br/estatisticas/ economicas/contas-nacionais/9052-sistema-de-contas-nacionais-brasil.html?=\&t=downloads. Acesso em: 5 jun. 2020.

IBGE - INSTITUTO BRASILEIRO DE ESTATÍSTICA E GEOGRAFIA. Pesquisa nacional por amostra de domicílios contínua. Mercado de Trabalho Conjuntural, Divulgação Mensal jan de 2020. Rio de Janeiro: IBGE, 2020b.

JACINTO, P. A.; RIBEIRO, E. P. Crescimento da produtividade no setor de serviços e da indústria no Brasil: Dinâmica e heterogeneidade. Economia Aplicada, v. 19, n. 3, p. 401-427, 2015.

KRÜGER, J. J. Productivity and structural change: A review of the literature. Journal of Economic Surveys, v. 22, n. 2, p. 330-363, 2008.

KUZNETS, S. Modern economic growth: Findings and reflections. American Economic Review, v. 63 , n. 3 , p. $247-258,1973$.

MCMILLAN, M.; RODRIK, D.; VERDUZCO-GALLO, I. Globalization, structural change, and productivity growth, with an update on Africa. World Development, v. 63, p. 11-32, 2014.

OECD - ORGANISATION FOR ECONOMIC CO-OPERATION AND DEVELOPMENT. ISIC Rev. 3 Technology intensity definition. Paris: OECD Directorate for Science, Technology and Industry, 2011.

PADILLA-PÉREZ, R.; VILLARREAL, F. G. Structural change and productivity growth in Mexico, 1990-2014. Structural Change and Economic Dynamics, v. 41, p. 53-63, 2017.

PASINETTI, L. L. The notion of vertical integration in economic analysis. Metroeconomica, v. 25, n. 1, p. 1-29, 1973.

PASSONI, P. A. Deindustrialization and regressive specialization in the Brazilian economy between 2000 and 2014: A critical assessment based on the input-output analysis. 2019. Tese (Doutorado em Economia) - Universidade Federal do Rio de Janeiro, Rio de Janeiro, 2019.

PENEDER, M. Industrial structure and aggregate growth. Structural Change and Economic Dynamics, v. 14, n. 4, p. 427-448, 2003. 
ROCHA, F. Produtividade do trabalho e mudança estrutural nas indústrias brasileiras extrativa e de transformação, 1970-2001. Revista de Economia Política, v. 27, n. 2, p. 221-241, 2007.

RODRIK, D. Premature deindustrialization. Journal of Economic Growth, v. 21, n. 1, p. 1-33, 2016.

SINGH, L. Technological progress, structural change and productivity growth in the manufacturing sector of South Korea. World Review of Science, Technology and Sustainable Development, v. 1, n. 1, p. 37-49, 2004.

SOLOW, R. M. Technical change and the aggregate production function. The Review of Economics and Statistics, v. 39, n. 3, p. 312-320, 1957.

SQUEFF, G. C.; DE NEGRI, F. Produtividade do trabalho e mudança estrutural no Brasil nos anos 2000. In: DE NEGRI, F.; CAVALCANTE, L. R. (Orgs.). Produtividade no Brasil: desempenho. Brasília: IPEA, 2014, p. 249-280.

SRAFFA, P. Production of commodities by means of commodities. Cambridge: Cambridge University Press, 1960.

SYRQUIN, M. Patterns of structural change. In: CHENERY, H.; SRINIVASAN, T. N. Handbook of development economics. Amsterdam: North Holland, 1988, p. 203-273.

TANG, J.; WANG, W. Sources of aggregate labour productivity growth in Canada and the United States. Canadian Journal of Economics, v. 37, n. 2, p. 421-444, 2004.

TIMMER, M. P.; SZIRMAI, A. Productivity growth in Asian manufacturing: The structural bonus hypothesis examined. Structural Change and Economic Dynamics, v. 11, n. 4, p. 371-392, 2000.

TIMMER, M. P.; VRIES, G. J. de. Structural change and growth accelerations in Asia and Latin America: A new sectoral data set. Cliometrica, v. 3, n. 2, p. 165-190, 2009.

UNCTAD - UNITED NATIONS CONFERENCE ON TRADE AND DEVELOPMENT. Free market commodity price indices, annual, 1960-2016. Geneva: Unctad, [2020]. Disponível em: http://unctadstat.unctad.org/wds/TableViewer/tableView.aspx?ReportId=30728. Acesso em: 5 jun. 2020.

VRIES, G. J.; TIMMER M. P.; VRIES, K. Structural transformation in Africa: Static gains, dynamic losses. The Journal of Development Studies, v. 51, n. 6, p. 674-688, 2015. 